\title{
Biometry of Female Genital Organs of Black Bengal Goat
}

\author{
Gupta $\mathrm{MD}^{1^{*}}$, Akter $\mathrm{MM}^{2}$, Gupta $\mathrm{AD}^{1}$ and Das $\mathrm{A}^{3}$ \\ ${ }^{1}$ Department of Microbiology, ${ }^{2}$ Department of Dairy and Poultry Science and ${ }^{3}$ Department of Genetics and \\ Animal Breeding, Faculty of Veterinary Medicine, Chittagong Veterinary and Animal Sciences University, \\ Khulshi,Chittagong-4202, Bangladesh.
}

[Received: 11 December 2010, Accepted: 04 March 2011]

\begin{abstract}
This study was conducted to establish the normal dimensions of the different segments of the female reproductive tract of the Black Bengal goats. The reproductive tracts of 56 adult non-gravid, female Black Bengal goat were collected and biometric parameters of different segments of the female reproductive tracts i.e. vulva, vagina, cervix, uterine body, uterine horns, oviducts and ovaries were measured .The lengths of the right and left ovaries were $1.453 \pm 0.034$ and $1.410 \pm 0.026 \mathrm{~cm}$, respectively. Mean weight of left ovary was $0.5944 \pm 0.06 \mathrm{gm}$ and that of right ovary was $0.614 \pm 0.07 \mathrm{gm}$ in Black Bengal goat. The average numbers of follicle in right and left ovaries were $4.123 \pm 0.230$ and $3.893 \pm 0.229$, respectively. The mean lengths of the vulva, vagina, cervix, uterine body, uterine horns and oviduct were $2.671 \pm 0.063$, $7.132 \pm 0.165,3.348 \pm 0.113,2.50 \pm 0.112$ and $12.287 \pm 0.270$ and $10.150 \pm 0.228 \mathrm{~cm}$, respectively. The width of the vagina, cervix, uterine body and uterine horn were $3.972 \pm 0.098,1.7551 \pm 0.042,2.739 \pm 0.079$ and $2.805 \pm 0.069 \mathrm{~cm}$, respectively. The average number of curuncle in uterus was $54.714 \pm 1.70$. A significant difference $(\mathrm{p}<0.05)$ between right and left ovaries was found for ovario-bursal adhesion. The mean weight, length and width in the present study were found higher in right ovaries than those of left ovaries.
\end{abstract}

Key wards: Black Bengal goat, biometric parameters, ovary, uterus, cervix, vagina.

\section{INTRODUCTION}

The Capra hircus species is a domestic animal in which the reproductive physiology is least understood compared to cattle, sheep and pig. Description of goat is usually made as if it is identical with sheep ${ }^{[1]}$. The goat is perhaps the most misunderstood and neglected, but nevertheless important species of livestock in the third world countries. Among the Asiatic countries, Bangladesh, a tropical agro-based developing country, possesses the third largest repository of goats, with a population of more than 34 million heads, according to the FAO ${ }^{[2]}$. This figure represents more than $37 \%$ of total livestock in Bangladesh. More than $90 \%$ of the goats of Bangladesh are of the Black Bengal breed ${ }^{[2]}$. The black bengal goat of Bangladesh is well reputed as prolific breed, and one of the main sources of foreign exchange earning of our national economy.

Reproductive performance is economically important in small ruminant because of its effect on the number of offspring produced per year ${ }^{[3]}$. To maintain a good reproductive performance a clear idea about the reproductive organs of small ruminant is necessary. The biometry of genital tracts of the female reveals the overall well being of the animals. The knowledge of the biometrical status of female genital tract is essential to perform artificial insemination, pregnancy diagnosis and dealing with the infertility problems ${ }^{[4]}$, and its treatment ${ }^{[5]}$. Modern technologies for increasing population such as Invitro Fertilization (IVF), Artificial Insemination (AI) requires a good knowledge of female reproductive biometry. For successful in vitro production (IVP) of embryos, the evaluation of ovaries, the efficient collection and grading of oocyte is very important. Extensive research on in vitro maturation (IVM), in vitro fertilization (IVF) and in vitro culture (IVC) of the resulting zygotes has so far been reported ${ }^{[6]}$ but limited information so far been available on the evaluation of goat ovaries and other genital organs. Control of diseases is also very important to ensure good health which also demands normal measurements of different reproductive tracts.

Some work on the morphology, physiology and pathology of reproductive organs of the goat ${ }^{77,8,9,10]}$ has been reported in different countries. But very little is known about the morphology of the reproductive tract of local black bengal goats of Bangladeash. Therefore, this study was aimed at to provide basic information regarding the anatomical structure of normal reproductive organs and to establish baseline data on the normal dimensions of different segments of the reproductive tract of the black bengal goat kept in Bangladesh.

\section{MATERIALS AND METHODS}

\section{Study area and time period}

The study was conducted on 56 female black bengal goats slaughtered at 4 abattoirs in Chittagong District of Bangladesh during June to August 2009. The abattoirs were Hathazari, Jhaotala bazar of Pahartali, CTG Cantonment (R.V.F.C) and Banskhali of Ctg.

Collection of Samples 
The samples were collected having negotiated with the butchers from each of these 4 selected abattoirs. During routine slaughtering operations the reproductive tracts of female Black Bengal goats were taken in plastic bag and marked the sample accordingly. This sample bag was initially kept in a refrigerator; eventually, all stored samples were sent to the Department of Anatomy and Histology, Chittagong Veterinary and Animal Sciences University, where all the samples were further stored at $-12^{\circ} \mathrm{C}$ until measured. Overall samples were collected from over a 56 adult non-gravid female black bengal goats.

\section{Laboratory and Sample preparation}

Before the measurement all logistics were collected and prepared in the laboratory. A metric ruler, an electronic balance, a large dissection tray and hand gloves were collected. The tray and electronic balance were placed on laboratory table in bright light area. Thawing was carried out by placing the frozen specimens in cold water.
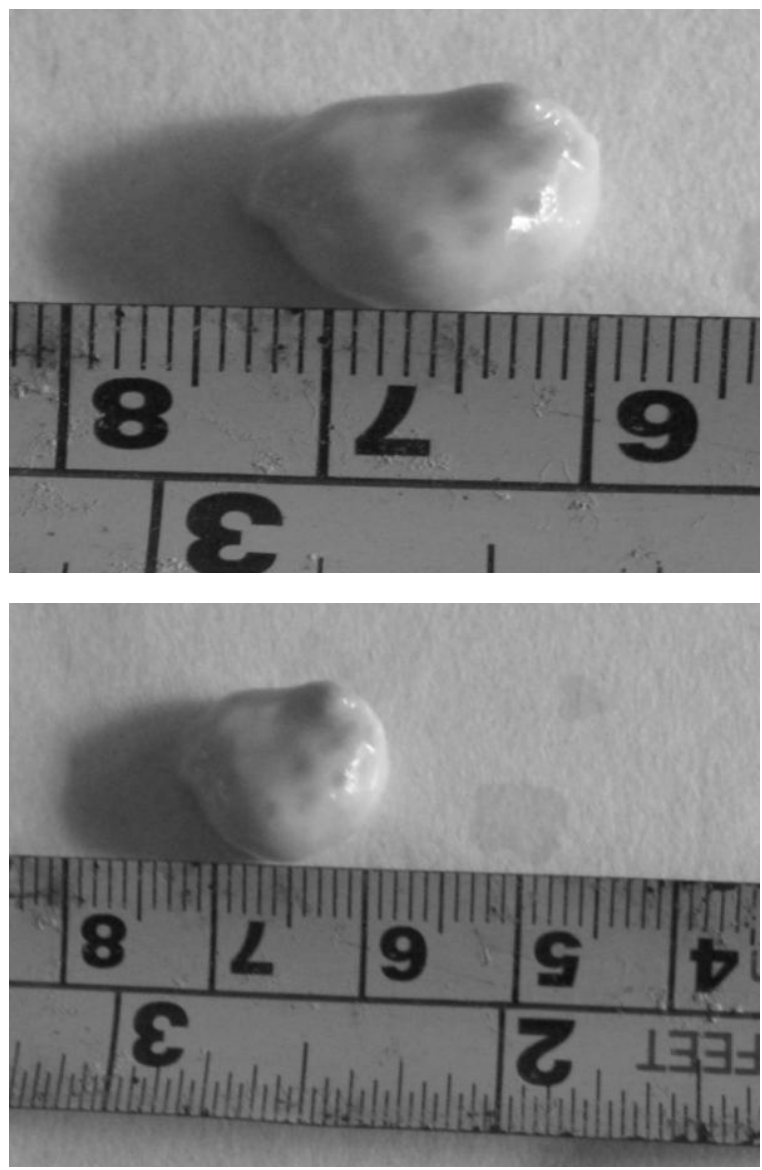

Figure 1: Measurement of the Length and width of Ovary

\section{Specimen Examination and Biometrical measurement}

Examination of the specimens was carried out under bright light. All measurements were recorded in centimeters and all weights in grams. In addition, the specimens were examined for gross abnormalities.
The organs were cleaned and freed from adhering tissues and placed on a table in normal position. Different segments of the tracts i.e. vulva, vagina, cervix, uterine body, uterine horns, oviducts and ovaries were measured. The reproductive tracts were measured using metric rule, thread and hand lens. The ovaries were removed at their junction with the ovarian ligament -as close to the ovarian tissue as possible after the fimbria was removed. The length of ovary was taken along the excision from the ovarian ligament and the width as the greatest line perpendicular to the length line (Fig.1). The weight of the ovary was measured using electrical balance. The follicles and corpus luteum were counted in each ovary using magnifying glass ${ }^{[11]}$. The oviducts were dissected out, and a measurement taken on their extended length from the top of the fimbriae to the tubal uterine horn junction. The lengths of the oviducts were taken from the uterotubal junction to the fimbriae (Fig. 2) and the diameters calculated from the circumferences ${ }^{[11]}$.

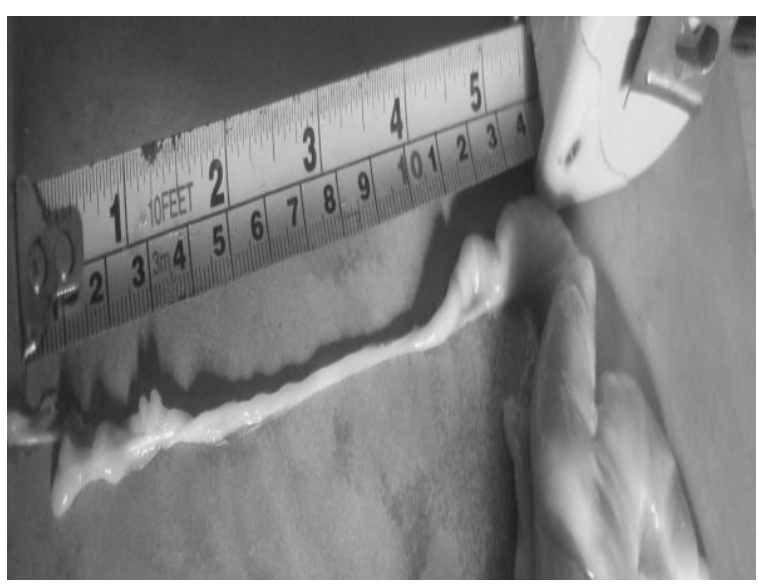

Figure 2: Measurement of the Length of Fallopian Tube

The uterine horns were dissected free of their ligamentous attachments, and extended their full length for measurement. Each uterine horn was incised along its dorsal surface to expose its lumen from the oviduct tubal junction to the bifurcation of the body of the uterus (Fig. 3). The body of the uterus was also incised, and this dorsal incision continued in a straight line to the dorsal commissure of the vulva in order to fully expose the cervical canal and the vagina. This method of exposure gave the relative thickness of the walls of the uterine horns, body of the uterus, cervix and vagina. The length of the uterine body was taken from its bifurcation to the internal os of the cervix (Fig. 4). The length and condition of the cervix were recorded.

The cervical length was measured as the distance between the external os and internal os (Fig.5) and the diameter calculated from the circumference at the middle portion. The cervical folds were counted and their accentric folds were recorded. The length of the vagina was taken as the distance from the external os 
of the cervix to the ventral commissure of the vulva. A measurement of the vaginal width was regularly taken at a point approximately $3 \mathrm{~cm}$. from the external os of the cervix, prior to extending the dorsal incision through the vagina.
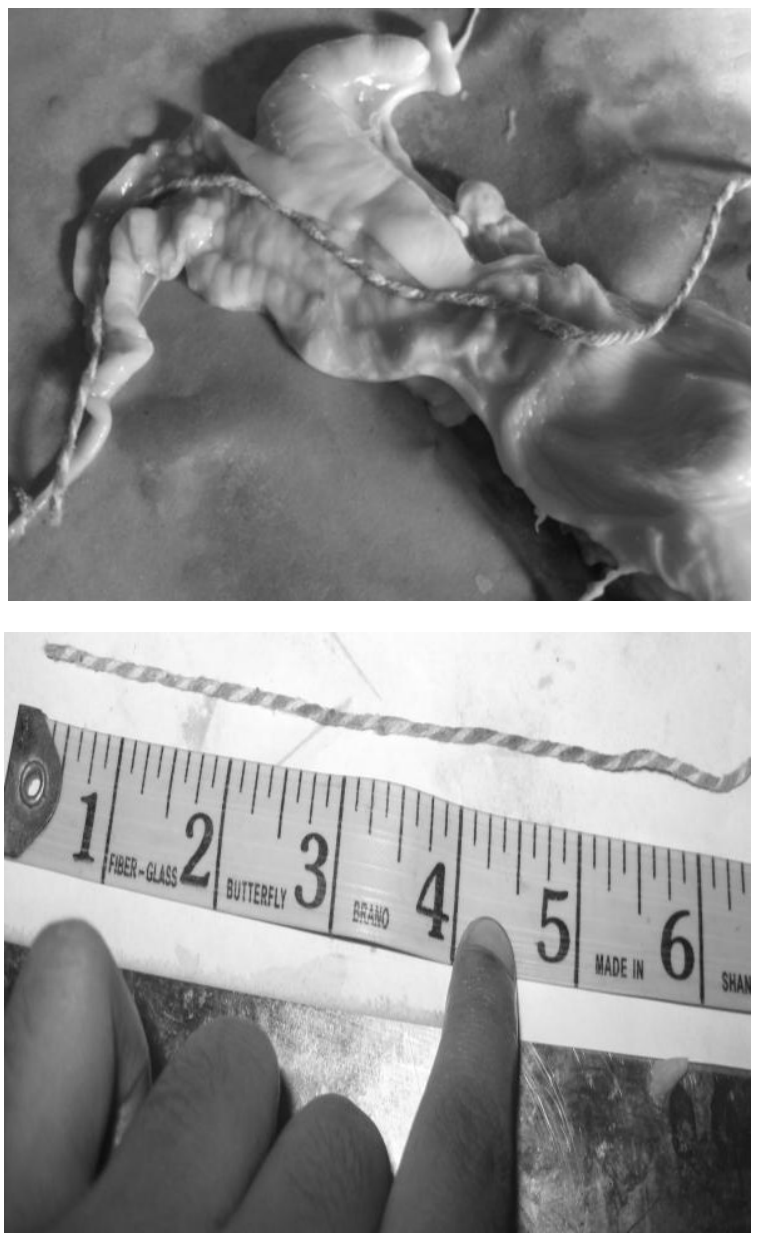

Figure 3: Measuring the Horn of the Uterus using thread

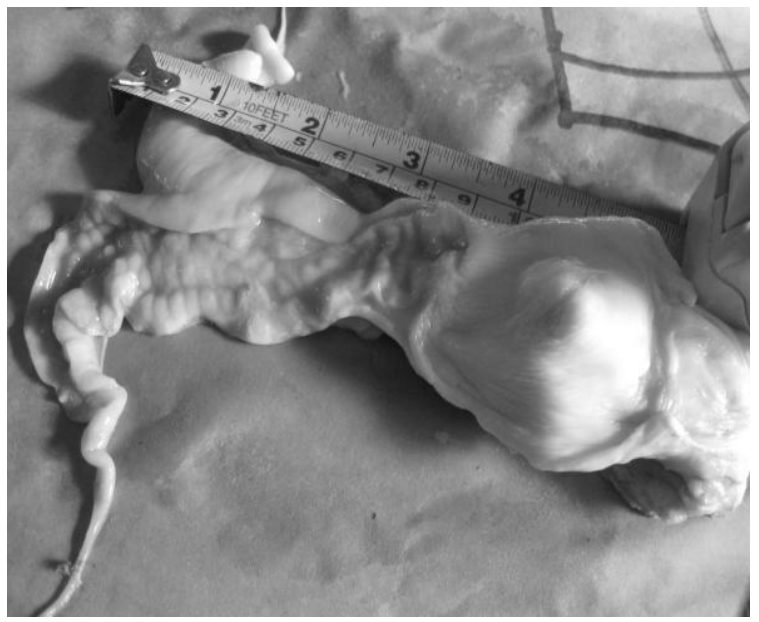

Figure 4: Measuring the length of uterine body

The length of the vulva was taken from the external vulva opening to the vestibule and that of the vagina from vestibule to the external cervical os ${ }^{[12]}$. For measurement of length and breath metric system was followed by using scales. Photograph and diagram were made for proper illustration of the observation. All measurements were taken with a thin, flexible, graduated steel tape.

\section{Statistical Analysis:}

All measurements were recorded in a tabular form. Then the tabulated data were entered into computer using Microsoft excel worksheet and analyzed for descriptive statistics. The significance between both right and left ovaries treatment and ovario-bursal adhesion was tested using SPSS (version-10).

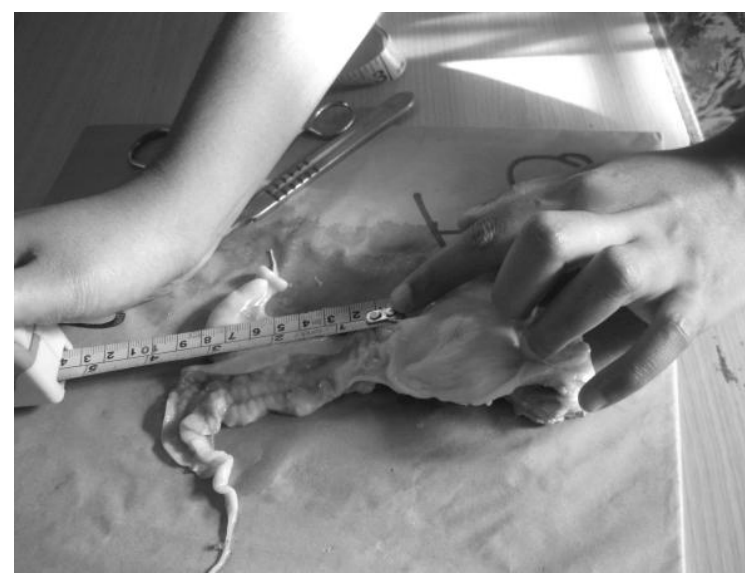

Figure 5: Measuring the length of cervix

\section{RESULTS AND DISCUSSION}

The mean length, width, weight, number of follicle and number of corpus luteum (CL) per ovary in Black Bengal goat are presented in Table 1. Table 2 shows the mean length and width of tubular part of reproductive tract of Black Bangle goat. The percentages of ovario-bursal adhesion in both right and left ovaries are presented in Table 3.

The ovaries of mature goat were almond shaped. The mean length of right ovary was higher than that of left ovary (Table 1). Comparatively a lower length for both right and left ovaries of goats was reported by Islam et al. ${ }^{[13]}$. However, a higher length was reported by Mohammadpur ${ }^{[14]}$ in Iranian native goat, Adigwe and Fayemi ${ }^{[15]}$ in Maradi goat of Nigeria and Sharma and Sharma ${ }^{[16]}$ in Gaddy goats of India, respectively. A significant $(\mathrm{p}<0.01)$ difference was found between the mean width of right and left ovaries (Table 1). The mean weight of the ovary recorded in the present study was lower than that of Islam et al. ${ }^{[13]}$. The mean number of follicle in the surface of each right and left ovary were higher than the value reported by Islam et al. ${ }^{[13]}$. Average number of CL in the surface of each right and left ovary was almost similar (Table 1). The mean length of the oviduct was $10.08 \pm 1.697$ in Black Bangle goat (Table-2).The finding of the present study was lower than the value $13.73 \pm 2.88 \mathrm{~cm}$ reported by Adigwe and Fayemi ${ }^{[15]}$. 
Table 1: The mean length, width, weight, number of follicle, and number of CL in each ovary of female Black Bengal goat.

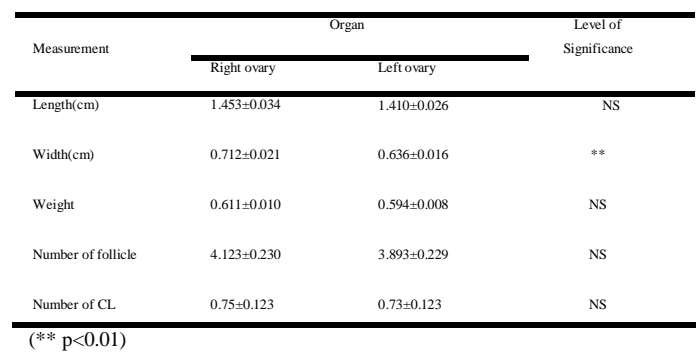

Table-2: The length and width (Mean \pm SD) of tubular part of reproductive tract of Black Bangle goat

\begin{tabular}{lll}
\hline \multicolumn{1}{c}{ Organ } & Length & Width \\
\hline Oviduct & $10.150 \pm 0.228$ & \\
Body of the uterus & $2.50 \pm 0.112$ & $2.739 \pm 0.079$ \\
Horn of the uterus & $12.287 \pm 0.270$ & $2.805 \pm 0.069$ \\
Cervix & $3.348 \pm 0.113$ & $1.7551 \pm 0.042$ \\
Vagina & $7.132 \pm 0.165$ & $3.972 \pm 0.098$ \\
Vulva & $2.671 \pm 0.063$ & \\
\hline
\end{tabular}

Table 3: Percentages of ovario-bursal adhesion in ovaries examined

\begin{tabular}{|c|c|c|c|c|c|c|}
\hline & \multicolumn{6}{|c|}{ Ovario-bursal adhesion } \\
\hline & & & negative & ositive & Total & $P$ value \\
\hline \multirow[t]{8}{*}{$\begin{array}{c}\text { ovary } \\
\end{array}$} & right ovary & $\begin{array}{c}\text { Count } \\
\end{array}$ & 45 & $\overline{11}$ & 56 & \\
\hline & & \% within ovary & $80.4 \%$ & $19.6 \%$ & $100.0 \%$ & \\
\hline & & $\begin{array}{l}\text { \% within } \\
\text { ovario-bursal } \\
\text { adhesion }\end{array}$ & $45.9 \%$ & $78.6 \%$ & $50.0 \%$ & 0.042 \\
\hline & & $\%$ of Total & $40.2 \%$ & $9.8 \%$ & $50.0 \%$ & \\
\hline & left ovary & Count & & & & \\
\hline & & \% within ovary & & & & \\
\hline & & $\begin{array}{l}\text { \% within } \\
\text { ovario-bursal }\end{array}$ & $54.1 \%$ & $21.4 \%$ & $50.0 \%$ & \\
\hline & & $\%$ of Total & $47.3 \%$ & & & \\
\hline \multirow{3}{*}{ Total } & & Count & & & & \\
\hline & & & 98 & 14 & 112 & \\
\hline & & $\%$ within ovary & $875 \%$ & $125 \%$ & $100.0 \%$ & \\
\hline
\end{tabular}

The mean length of uterine horns in Black Bangle goat (Table-2) was within the range $(10-12 \mathrm{~cm})$ reported by Sisson and Grossman ${ }^{[17]}$ in small ruminant. Comparatively a higher value was reported by Adigwe and Fayemi ${ }^{[15]}$. But the width of the uterine horn in Black Bengal goat was higher than that mentioned by Adigwe and Fayemi ${ }^{[15]}$ in Sokoto goat of Nigeria. Mean length of the body of uterus in Black Bangle goat (Table -2) were almost similar with the value reported by Sisson and Grossman ${ }^{[17]}$ but lower than that by Adigwe and Fayemi ${ }^{[15]}$.

The length of cervix recorded in this study was slightly higher than the value reported by Sisson and Grossmen ${ }^{[17]}$. The width recorded during the present study was slightly higher than the value reported by Adigwe and Fayemi ${ }^{[15]}$. The mean length and width of vagina of Black Bengal goat (Table-2) were consistant with the result of Rahman et al. ${ }^{[18]}$. However, findings of Sisson and Grossman [17]; Adigwe and Fayemi ${ }^{[15]}$ were lower than the present study. The mean length of vulva in Black Bengal Goat was found to be almost similar with the range reported by Sisson and Grossmen ${ }^{[17]}$ and higher than that the value obtained by Adigwe and Fayemi ${ }^{[15]}$.

Overall ovario-bursal adhesion found in the ovaries of the Black Bengal goat was $12.5 \%$. The percentages of ovario-bursal adhesion in right and left ovaries examined were 19.6 and 5.4, respectively. A significant difference $(\mathrm{p}<0.05)$ was found between right and left ovaries for ovariobursal adhesion (Table 3 ).

\section{CONCLUSION}

Right ovary was wider, larger in length and heavier in weight as compared to left one which confirm the fact of right ovary being more active than the left one. These results have established the baseline dimensions of the different segments of the female reproductive tract of the Black Bengal goat and the information will help the diagnosis of various abnormalities. The differences between the results in this study and published results in goats might be due to breed differences. Differences in size of reproductive tract may also be due to climatic effects as young goats in the tropics have to contend with the effects of the first dry season when growth may be seriously retarded. More work on other breeds, like the Jamnapari, cross breed, local and causes of differences between breeds and species seems important for better understanding of the reproduction in these animals.

\section{ACKNOWLEDGEMENTS}

The authors acknowledge Md. Abul Quasem, Professor, Department of Anatomy \& Histology, Major Harun, RVFC, Chittagong Cantonment and Dr. Mohammad Mejbah uddin Assistant Professor and Dr. A.S.M. Golam Kibria, Lecturer, Department of Anatomy and Histology, Faculty of Veterinary Medicine, Chittagong Veterinary and Animal Sciences University for their cooperation to pursue the research.

\section{REFERENCES}

1. Smith MC (1986). Caprine reproduction. In Current Therapy in Theriogenology, ed. DA Marrow, 577-579. Philadelphia, USA, W. B. Saunders.

2. Food and Agricultural Organization of the United Nations (FAO)(1999). Production Year Book. Rome, Italy 53:54-58. 
3. Greyling JPC (2000). Reproduction traits in the Boer goat doe. Small Rumin Res. 36 (2).171177.

4. Kunbhar HK, Samo MU, Memon A and Solangi AA (2003). Biometrical studies of Reproductive organs of Thari cow. Pakistan J. Biological Sci. $6(4): 322-324$.

5. Kumar S, Ahmed FA and Bhadwal MS (2004). Biometry of female genitalia of Murrah buffalo (Bubalus bubalis). Indian J. Anim. Reprod. 25(2):143-145.

6. Cognié Y, Baril G, Poulin N and Mermillod P. INRA (2003). Current status of embryo technologies in sheep and goat. Theriogenology. 59(1):171-188.

7. Moreira ELT, Nascimento EF dO and Chquiloff MAG (1991). Morphologic alterations in the ovaries and the uterus of Capra hircus L.I. Regressive alterations. Arquivos da Escola de Medicina. Veterinaria da Universidade, Federal de Bahia. 14 (1): 25-39.

8. Torres EB and Badiongan EH (1989). Postpartum macroscopic changes of the measurements of the reproductive organs of Philippine Nondescriptive goats. Philippine J. Vet. Anim. Sci. 15:74-79.

9. Epelu-Opio J, Weyrauch $\mathrm{KD}$ and Amongi $\mathrm{T}$ (1988). Fine structure of the oviductal epithelium in pregnant local Ugandan goat. Zeit fur Mikrosk Anat Forsh. 102(6): 977-984.

10. Sattar A, Khan MZ and Siddique M (1988). Incidence and pathology of ovarian diseases of goats. Pakistan Vet. J. 8:18-21.
11. Singh SK, Bhattacharya AR and Luktuke SN (1974). Studies on biometry of genital organs of female goat. Indian Vet. J. 51(2):81-85.

12. Drennan WG and Macpherson JW (1966). The Reproductive Tract of Bovine Slaughter Heifers (A Biometrical Study). Can. J. Comp. Med. Vet. Sci. 30 (8):224-227

13. Islam MR, Khandoker MAMY, Afroz S, Rahman MGM and Khan RI(2007). Qualitative and Quantitative analysis of goat ovaries, follicles and oocytes in view of in vitro production of embryos. J. Zhejiang University Sci. B. 8(7):465469.

14.Mahammadpour AA (2007). Comparative histomorphological study of ovary and ovarian follicles in Iranian Lori-Bakhtiari Sheep and Native goat. Pakistan J. Biological Sci.10 (4):673-675.

15. Adigwe PI and Fayemi O (2005). A Biometric study of the reproductive tract of the Red, Sokoto (Maradi) goats of Nigeria. Pakistan Vet. J. 25(3):149-150.

16. Sharma S and Sharma DN (2004). Biometrical study of internal genital organs of Gaddi goats. Indian J. Anim. Repord. 4(2):243-246.

17. Sisson S and Grossman JD (1972). Anatomy of the Domestic Animals. $5^{\text {th }}$ ed. Philadelphia, USA, W. B. Saunders.

18. Rahman A, Hossain A, Ahmed MU and Sen MM (1977). Studies on some reproductive performance and biometry of the female genital tract of Black Bengal goat. Ind. J. Anim. Sci. 724725 . 